\title{
Characterization of the rheology behavior of modified skim rubber
}

\author{
Linghong Zhang ${ }^{1, a}$, Tianming Gao ${ }^{2, b}$, Jiao Yang ${ }^{2, c}$, Hongxing Gui ${ }^{2, d}, K^{2} C_{h e n}^{2, e}$, \\ Maofang Huang $2, f$
}

1. Rubber Research Institute, Chinese Academy of Tropical Agriculture Science, Danzhou 571737, People's Republic of China
2. Agricultural Product Processing Research Institute, Chinese Academy of Tropical Agriculture Science, Zhanjiang 524001, People's Republic of China

a.zlh54@126.com, b.gaotmcat@163.com,c.253558538@qq.com; d.guihongxing@263.net, e.64435873@qq.com,f.huangmaofang666@163.com

Keywords: modified skim rubber; rheology behavior; rubber process analyzer

Abstract: Test of the rheology behavior for modified skim rubber (MSR) were carried out with rubber processing analyzer (RPA), and mooney viscosity were carried out with Mooney Viscometer. The results showed that mooney viscosity of MSR is lower than skim rubber, and it is higher than SCR-5 (Chinese Standard Rubber-5). The complex viscosity ( $\left.\mathrm{n}^{*}\right)$ and the stress relaxation have same results with mooney viscosity, that MSR's is higher than SCR-5 and lower than skim rubber. The elastic torque (S') is increased with the frequency rising, and the S' of MSR is in the middle of the all samples.

\section{Introduction}

Skim rubber latex is a byproduct of concentration process of natural rubber latex. After concentration of field latex, about 5-8\% dry rubber content is left in skim rubber latex, and higher nonrubber proportion and ammonia content are obviously feature of skim latex.[1] Concerning of skim rubber, it has about $80 \%$ rubber hydrocarbon, and more than $10 \%$ protein. Howerver, it has about $95 \%$ rubber hydrocarbon and $2 \%$ protein in natural rubber.[2]

Standard of chinese rubber (SCR) is classificated natural rubber in china, and it includes SCR-WF, SCR-5, SCR-10, SCR-20. According to chinese standard (GB/T 8081-2008), identified grade of natural rubber is accorded to impurity, ash, nitrogen, volatile matter, $\mathrm{P}_{0}$ and PRI (for short: six indexes). Meanwhile, NY/T 229-2009 is occupation standard of skim rubber in china. It is easy to find that standard of impurity, ash, nitrogen and volatile matter for skim rubber is higher than SCR-5, and standar of PRI for skim rubber is lower than SCR-5.[3,4] In addition, thermal oxidative degradation of skim rubber is poorer than NR, and mechenical properties and aging characteristics are worse than NR.[5]

Rubber processing analyzer(RPA) is a dynamic mechanical rheological tester designed to provide dynamic property data on rubber polymers, master batches, uncured compounds, and cured compounds. The natural rubber with different molecular weight and molecular structure will have different viscoelastic properties. Therefore, it is very convenient to apply RPA for research on the viscoelastic properties of raw rubber and it could be used for characterization the molecular weight of NR.

In this work, we focused on decreased the nitrogen content and improved the PRI of skim rubber. Moreover, the dynamic properties of modified skim rubber, skim rubber and SCR-5 were compared. 


\section{Materials and methods}

\section{Material and reagent}

SCR-5, skim rubber and skim latex were obtained from Hainan rubber group. Other chemicals were all commercial grade.

\section{Preparation of modified skim rubber}

The skim rubber latex was incubation with alkaline protease, stay $24 \mathrm{~h}$ at the room temperature. The reacted latex was coagulated by formic acid and sheeting, size-reducing granulate, drying

\section{Characterization of skim rubber and other rubber samples \\ Mooney viscosity $\left[\mathrm{ML}(1+4) 100^{\circ} \mathrm{C}\right]$}

The $\mathrm{ML}(1+4) 100^{\circ} \mathrm{C}$ was determined using a Mooney Viscometer (UM-2050, U-CAN, Taiwan) according to chinese standard: GB/T 1232.1-2000.

\section{RPA analysis}

An RPA2000 (Alpha Technologies, Akron, OH, USA) was used for dynamic and rheological measurements. The samples were cut from milled NR of about $6 \mathrm{~g}$ and placed into moulding chamber. The strain sweep was carried out at a frequency of $10 \mathrm{cpm}$ and at a temperature of $60^{\circ} \mathrm{C}$, and the frequency sweep was carried out at $0.5^{\circ}$ of arc and $100^{\circ} \mathrm{C}$. The stress relaxation was measured at $5^{\circ}$ of arc and $60^{\circ} \mathrm{C}$, and the test time was $2 \mathrm{~min}$.

\section{Results and discussion}

\section{Mooney viscosity}

The Mooney viscosity is a basic parameter for characterizing NR, and is used to evaluate the average molecular weight of the rubber material. Table 2 shows the ML(1+4) of skim rubber, modified skim rubber and SCR-5. It showed that skim rubber have highest mooney viscosity, and SCR-5 have the lowest mooney viscosity.

Table. 1 mooney viscosity of modified skim rubber, skim rubber and SCR-5

\begin{tabular}{lccc} 
& Skim rubber & $\begin{array}{c}\text { Modified skim } \\
\text { rubber }\end{array}$ & SCR-5 \\
$\begin{array}{c}\text { Mooney viscosity } \\
{\left[\mathrm{ML}(1+4) 100^{\circ} \mathrm{C}\right]}\end{array}$ & 81.26 & 74.86 & 71.91 \\
\hline
\end{tabular}

\section{rheology behavior}

Shear rate $(r)$ is one of important parameter in RPA. Various strains can product different shear rates $(r)$, and we can obtain series data according to shear rates. The relation between the apparent viscosity $n^{*}$ and shear rate $(r)$ can be expressed as follows:

$n^{*}=k \cdot r^{n-1}$

where $k$ and $n$ are constants of rubber. The complex viscosity, $n^{*}$, obtained from RPA is used as $n^{\alpha}$ in our work because $n^{*}$ corresponds well to the $n^{\alpha}$ value obtained from a capillary rheometer. A plot of $\ln \left(n^{*}\right)$ versus $\ln \left(r_{s}\right)$ according to eq. (1) (see Fig. 1). Results show that there is a flat zone in range of low $\ln \left(r_{s}\right)$. With the $\ln \left(r_{s}\right)$ change, $\ln \left(n^{*}\right)$ exhibit straight line that is almost parallel to the $\ln \left(r_{s}\right)$ axis, and the constant $\mathrm{n}$ is approximately 1 ; this is a feature of Newtonian behavior. In the range of high $\ln \left(r_{s}\right)$ values, with $\ln \left(r_{s}\right)$ rise $\ln \left(n^{*}\right)$ decreases, this phenomenon is called shear thinning, a feature of non-Newtonian behavior (pseudoplastic behavior). Fig1 exhibits that skim rubber has highest $n^{*}$, and SCR-5 has lowest $n^{*}$.

A plot of $\ln \left(n^{*}\right)$ versus $\ln \left(r_{f}\right)$ (see Fig. 2) illustrates a change in $\ln \left(n^{*}\right)$ that is different from that in Figure 1; that is, the decrease in $\ln \left(n^{*}\right)$ is linearly related to the increase in $\ln \left(r_{f}\right)$ over the whole 
range of $\left(r_{f}\right)$ values, and the slope of the straight line decreases with the prolongation of the aging time. On the basis of the changes in $\left(n^{*}\right)$ with $(r)$ shown in Figures 1 and 2, according to the drop in the value of $\ln \left(n^{*}\right)$ expressed by the straight line in Figure 1 and the decrease in the slope of the straight line in Figure 2, it show that skim rubber has the highest viscosity and SCR-5 has the lowest viscosity. It may be assume that this is caused by nonrubber component in skim rubber.

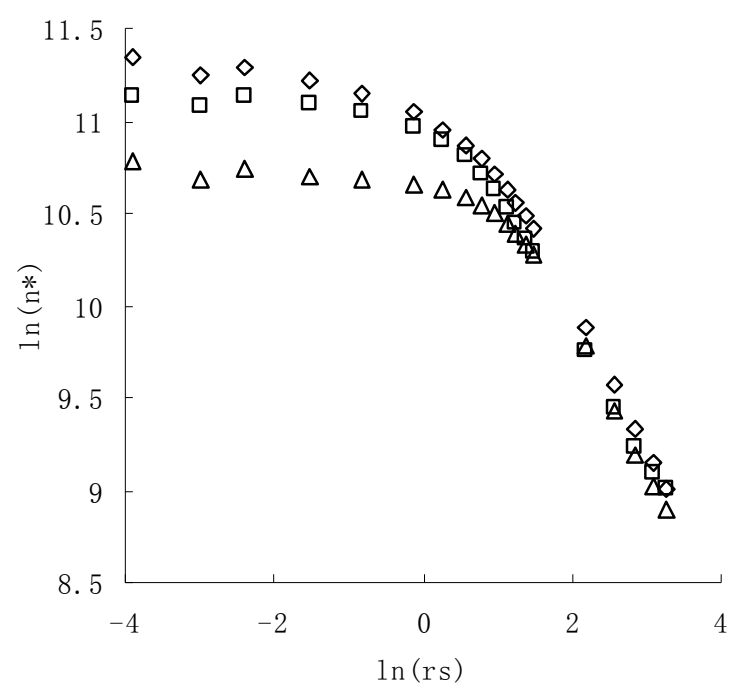

Fig.1 Relation between $\ln \left(n^{*}\right)$ and $\ln \left(r_{s}\right)$, $(\diamond$-skim rubber; $\triangle$-SCR-5; $\square$-modified skim rubber;)

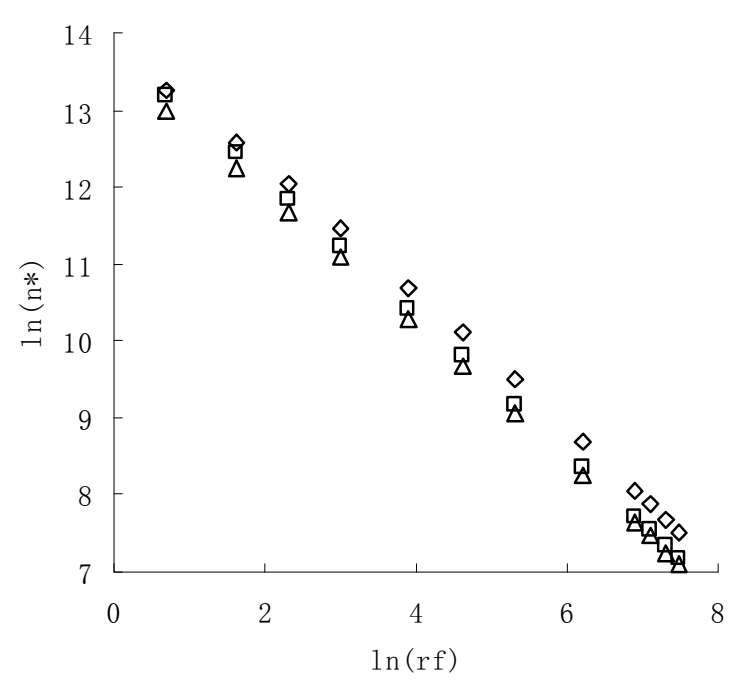

Fig.2 Relation between $\ln \left(n^{*}\right)$ and $\ln \left(r_{f}\right)$, $(\diamond$-skim rubber; $\triangle$-SCR-5; $\square$-modified skim rubber;)

\section{Stress relaxation}

Stress relaxation is represent the molecular weight of natural rubber. Due to the molecular entanglement of higher molecular weight in natural rubber, it causes the longer relaxation time.[6] According to the figure 3, the time of complex torques reduce to $64 \%$ of the original values are 0.24 min for skim rubber, 0.12 for MSR and 0.068 for SCR-5. It exhibit that the skim rubber has longest relaxation time and SCR-5 has the shortest relaxation time, and the results had the close relationship with mooney viscosity.

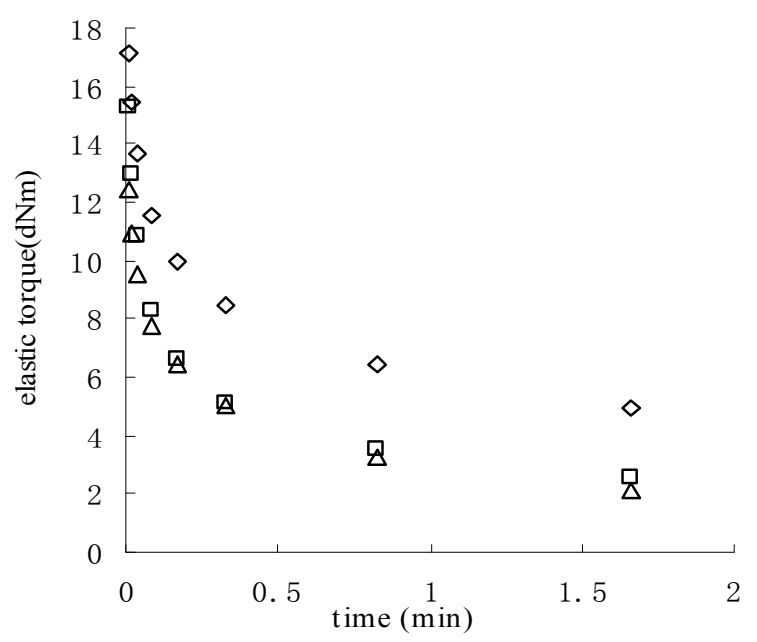

Fig.3 Stress relaxation Relation between torque(S') and time ( $\diamond$-skim rubber; $\triangle$-SCR-5; $\square$-modified skim rubber;)

\section{Frequency sweep}

The elastic torque ( $\mathrm{S}^{\prime}$ ) response from the frequency sweep is sensitive to rheological differences 
among polymers.[7] Fig. 4 shows that the curve of the S' response from frequency sweep. With the rise of the frequency, the $S$ ' is increasing. In addition, skim rubber has highest S', and SCR-5 had the lowest S'. That is caused of skim rubber has higher moomey viscosity and higher relative molecular weight.

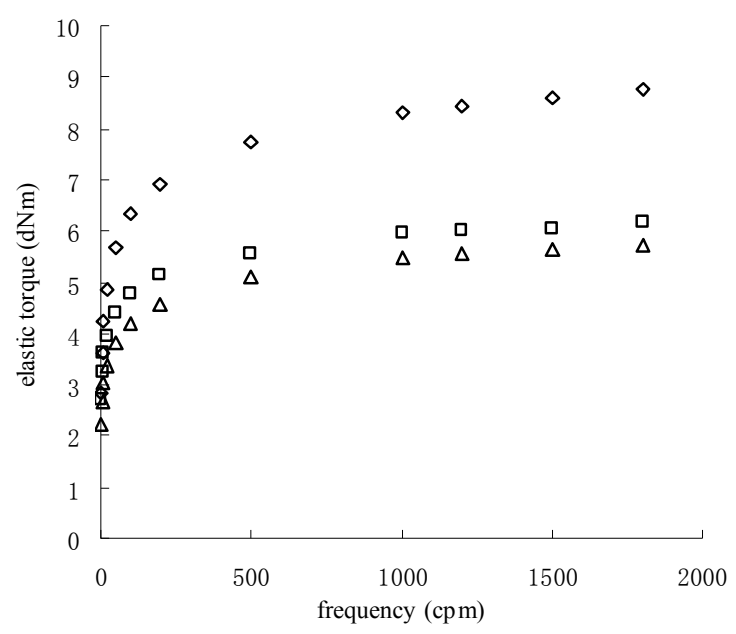

Fig.4 Relation between torque (S') and strain ( $\diamond$-skim rubber; $\triangle$-SCR-5; $\square$-modified skim rubber;)

\section{Conclusion}

1. The mooney viscosity of modified skim rubber is lower than skim rubber and higher than SCR-5.

2. The changes in $n^{*}$ with $r$ show that NR behaves like Newtonian flow in the range of low $r$ values and like non-Newtonian flow (pseudoplastic behavior) in the range of high $r$ values. The results are well correspondence with mooney viscosity.

3. The stress relaxation rate has signification relationship with mooney viscosity in rubber. It exhibit mooney viscosity has well relationship with stress relaxation.

4. The results of the S' response from frequency sweep is same as mooney viscosity, that is the values of MSR is close to SCR-5.

\section{Acknowledgements}

It is a pleasure to acknowledge the generous financial support by earmarked fund for china agriculture research system (CARS-34-GW9) and the Fundamental Research Funds for Rubber Research Institute, CATAS (1630022014013).

\section{References}

[1] Hou Ting-ting, Zhong Jie-ping, Lv Ming-zhe, Li Cheng-peng, Yang Lei, Li Si-dong, Study on Thermal Oxidation Degradation of Purified Skim Rubber. Guangzhou Chemistry. 35 (2007) 29-31.

[2] K. Mariamma George, Rosamma Alex, Susamma Joseph, K. T. Thomas, Characterization of Enzyme-Deproteinized Skim Rubber. Journal ofAppliedPolymer Science. 114 (2009) 3319-3324.

[3] GB/T 8081-2008, Natural rubber Standard of Chinese Rubber.

[4] NY/T 229-2009, Natural rubber, Skim rubber

[5] Khosit Simma, Garry L. Rempel, Pattarapan Prasassarakich, Improving thermal and ozone stability of skim natural rubber by diimide reduction. Polymer Degradation and Stability. 94 (2009) 
1914-1923.

[6] Zheng changren. Molecule weight and distribution of polymer. Chemical industry press. 1986, 26.

[7] Dick, J.; Pawlowski, H. (1994) Presented at the Meeting of the Rubber Division of the American Chemical Society, Chicago, IL. 